\title{
Papel del TGF- $\beta$ en la inmunidad contra los rotavirus
}

\author{
Manuel Antonio Franco-Cortés \\ Instituto de Genética Humana, Pontificia Universidad Javeriana, Bogotá, Colombia
}

\begin{abstract}
Resumen
La vía de entrada y el principal sitio de replicación de los rotavirus es el intestino delgado. En este órgano el TGF- $\beta$ juega un papel muy importante para mantener la tolerancia a los alimentos y microorganismos comensales. Por esta razon, es probable que esta citocina juegue un papel modulador en esta infección. Experimentos in vitro de nuestro laboratorio han mostrado que células humanas epiteliales infectadas por rotavirus aumentan la secreción de TGF- $\beta$ y promueven una baja respuesta de linfocitos $\mathrm{T}$, la que es necesaria para la inmunidad antiviral. En este artículo de revisión se analiza en forma crítica la hipótesis que los rotavirus inducen la producción de TGF- $\beta$ como mecanismo de evasión inmune.
\end{abstract}

Palabras clave: rotavirus, inmunidad intestinal, factor de crecimiento transformante Beta, tolerancia inmunológica, evasión inmunológica de virus.

\section{Role of TGF- $\beta$ in rotavirus immunity}

\begin{abstract}
Rotavirus enter their host and predominantly replicates in the small intestine. In this organ, TGF- $\beta$ plays an important role in maintaining tolerance to commensal microorganisms and food. For this reason, it is probable that this citokine plays a role in modulating viral infection. Results from our laboratory have shown that in vitro human cells infected with rotavirus secrete increased levels of TGF- $\beta$ and promote an attenuated T cell response, which is necessary for protective cellular immunity. In this review article, I will critically evaluate the hypothesis that rotavirus induce the production of TGF- $\beta$ as an immune evasion mechanism.
\end{abstract}

Key words: Rotavirus, intestinal immunity, transforming growth factor beta, immunological tolerance, viral immune evasion.

\section{Introducción}

El desarrollo de vacunas contra los rotavirus es un importante logro de la medicina moderna (Angel, et al., 2014). Sin embargo, las vacunas actualmente en uso son relativamente poco eficientes en los países en vías de desarrollo, donde son más útiles, y es importante entender mejor la inmunidad antiviral para mejorarlas (Angel, et $\boldsymbol{a l}$. , 2014). La inmunidad que inducen los rotavirus no es esterilizante y en muchos casos es de corta duración (Angel, et al., 2012; Franco, et al., 2006). Es probable que durante el desarrollo de la respuesta inmune contra estos virus entren en juego mecanismos que favorecen una respuesta protectora, elementos reguladores negativos de la respuesta inmune $\mathrm{y}$, por último, las estrategias que ha desarrollado el virus para escapar a ésta (Angel, et al., 2012). El sistema inmune cuenta, entre otros, con 3 poderosos reguladores negativos: La proteína "muerte programada 1" (PD-1), la interleucina 10 (IL-10) y el factor de crecimiento transformante beta (TGF- $\beta$ ) (Freeman, et al., 2014; Garidou, et al., 2012). Dado que la principal puerta de entrada y sitio de replicación de los rotavirus es el intestino delgado, donde el TGF- $\beta$ juega un papel muy importante para mantener la tolerancia a los alimentos y microorganismos comensales (Travis and Sheppard, 2014), es muy probable que esta citocina juegue un papel modulador en esta infección (Angel, et al., 2012). Nuestros resultados en modelos in vitro han mostrado que células humanas epiteliales infectadas por rotavirus aumentan la secreción de TGF- $\beta$ y promueven una baja respuesta de linfocitos T (LT) necesaria para la inmunidad y protección antiviral (Barreto, et al., 2010; Mesa, et al., 2010; Rodríguez, et al., 2009; Rodriguez, et al., 2012). En este artículo revisaré en forma crítica la hipótesis que el rotavirus induce la producción de TGF- $\beta$ como mecanismo de evasión inmune. Para poner en contexto la discusión, primero se revisarán aspectos generales de lo que se conoce acerca de cómo funciona el TGF- $\beta$ en el sistema inmune, seguido de cómo los patogenos han explotado al TGF- $\beta$ para evadir a este sistema. Finalmente, se revisará

\footnotetext{
Correspondencia:

Manuel Antonio Franco-Cortés, mafranco@javeriana.edu.co

Recibido: 25 de octubre de 2015

Aceptado: 15 de febrero de 2016
} 
la literatura que ha implicado al TGF- $\beta$ en la inmunidad contra rotavirus in vitro e in vivo en los modelos murino, porcino y humano.

\section{El TGF- $\beta$ en la respuesta inmune}

El TGF- $\beta$ es una citocina clave en la respuesta inmune y en particular en mantener el ambiento tolerogénico del intestino y en la inducción de tolerancia después de la administración oral de un antígeno (Lin, et al., 2005; Travis and Sheppard, 2014; Weiner, et al., 2011). En los mamíferos, la familia de proteínas del TGF- $\beta$ incluye tres miembros: TGF- $\beta$ 1, 2 y 3 , con gran homología, pero diferencias en sus efectos y mecanismos de acción (Travis and Sheppard, 2014). Cada una de las isoformas es sintetizada como un precursor que incluye: un péptido señal, un gran fragmento N-terminal llamado el péptido asociado a latencia (latency-associated peptide, en inglés LAP) y un pequeño fragmento C-terminal que es la citocina propiamente dicha (Travis and Sheppard, 2014). Existen múltiples mecanismos (el sistema de la trombospondina, varias integrinas, etc) para retirar el LAP, lo cual hace que la citocina cobre actividad y que permiten regular su función de una forma diferencial y específica de órgano (Travis and Sheppard, 2014; Worthington, et al., 2015).

El receptor del TGF- $\beta$ está compuesto por dos subunidades del receptor de tipo I (TGF-bRI) y dos del receptor de tipo II (TGF-bRII). Las tres isoformas de la citocina inicialmente se unen al homodímero del TGF-bRII. Este complejo se une a un homodímero del TGF-bRI, lo que permite que el TGF-bRII fosforile el dominio citoplasmático de este último complejo e induzca la señalización celular a través de las proteínas de la familia SMAD (Travis and Sheppard, 2014).

El TGF- $\beta$ es producido por un gran número de células y en particular macrófagos (Travis and Sheppard, 2014), y puede tener efectos muy diferentes dependiendo de la presencia de otros factores secretados o correceptores celulares. Por un lado, puede disminuír la respuesta inmune adaptativa por medio de la inducción y estabilización de la función de los LT reguladores (LTreg) o directamente suprimiendo a los LT CD4 Th1, Th2 y los LT CD8. Por otro lado, dependiendo del contexto, puede incrementar respuestas adaptativas mediante la inducción de células Th17, Th9 y LT CD4 con efecto citolítico (Travis and Sheppard, 2014). Por esta razon el TGF- $\beta$ puede en ciertas circunstancias promover la persistencia de patógenos cuando su efecto neto es anti-inflamatorio o lo contrario cuando es proinflamatorio (Figura 1). El que ocurra uno u otro tipo de efecto esta determinado principalmente por las citocinas que existan concomitantemente (Figura 1). Recientemente se ha visto que el TGF- $\beta$ promueve el desarrollo de Thf específicos del virus de la influenza (Marshall, et al., 2015) y el desarrollo de los LT residentes en el intestino (Zhang and Bevan, 2013). Igualmente se ha descrito una nueva subpoblación de LTreg llamados LTr1 que son Foxp3-, IL-

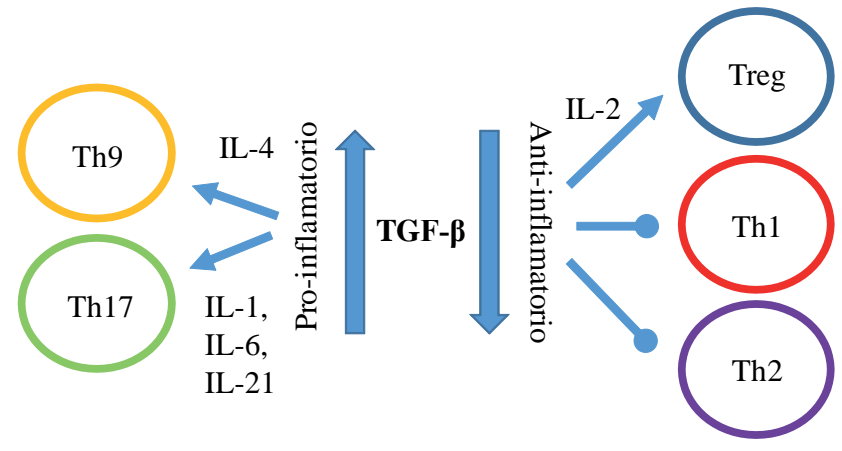

Figura 1. El TGF- $\beta$ puede tener efectos pro-inflamatorios o anti-inflamatorios al estimular o inhibir el desarrollo de subtipos de LT dependiendo del contexto de las citocinas que estén concomitantemente presentes. Los datos son tomados de (Travis and Sheppard, 2014). Las flechas indican un efecto estimulador. Las esferas un efecto inhibitorio.

10+ (Gagliani, et al., 2015). Los LTr1 juegan un papel crítico en la resolución de la inflamación y tolerancia a nivel del intestino y su desarrollo es dependiente de TGF- $\beta$ (Gagliani, et al., 2015).

La principal isoforma expresada en el sistema inmune es el TGF- $\beta 1$ y los ratones deficientes en ella mueren por un síndrome autoinmune inflamatorio multisistémico a las 3-4 semanas de edad. Al cruzar ratones deficientes de TGF- $\beta 1$ con aquellos deficientes de moléculas del complejo mayor de histocompatibilidad la respuesta inflamatoria y autoinmune se ve disminuída (Travis and Sheppard, 2014). Más aún, ratones en los cuales se elimina el TGF-bRII exclusivamente en los LT, también desarrollan este síndrome autoinmune, lo que indica que la respuesta inmune adaptativa es un blanco fundamental para el TGF- $\beta$ (Zhang and Bevan, 2012). Los ratones en los cuales se expresa una forma dominante-negativa del TGF-bRII (a partir de un promotor modificado del CD4, ratones CD4dnTGF-bRII) la señalización del TGF- $\beta$ se ve atenuada tanto en LT CD4 como LT CD8. Además, debido a que el fenotipo autoinmune sólo aparece a los tres o cuatro meses de edad, estos ratones han sido útiles para estudiar el papel del TGF- $\beta$ en el sistema inmune (Tinoco, et al., 2009). Sin embargo como se discute mas extensamente abajo los resultados con estos ratones son dificiles de interpretar pues tienen una respuesta de LT exagerada dependiente del transgene ya que esta respuesta no se observa en los ratones a quienes se elimina el TGF-bRII (Ishigame, et al., 2013a; Ishigame, et al., 2013b). Más recientemente se han utilizado ratones en los cuales la deleción del TGF-bRII se realiza a partir de un promotor distal del gen Lck, que sólo se expresa después de la selección positiva de los LT en el timo, y estos ratones no desarrollan autoinmunidad, pero sus LT si median autoinmunidad cuando se transfieren a individuos linfopénicos (Zhang and Bevan, 2012, 2013). 
Uno de los principales mecanismos por los cuales el TGF- $\beta$ media su efecto en el sistema inmune son los LTreg. Un subtipo de los LTreg Foxp3 ${ }^{+}$expresan en su membrana una forma madura del TGF- $\beta$ con un efecto funcional que puede ser bloqueado con anticuerpos neutralizantes (Travis and Sheppard, 2014). Sin embargo, se ha visto que LT CD4 Foxp3 3 pueden expresar otra forma de TGF- $\beta$ que no es susceptible a estos anticuerpos neutralizantes, pero si a un nuevo grupo de anticuerpos específicos de LAP murino (da Cunha, et al., 2015; Oida and Weiner, 2011; Rezende, et al., 2013). El papel fisiológico de esa nueva forma de TGF- $\beta$ no es muy claro, pero induce una vía de señalización idéntica al TGF- $\beta$ clásico, inhibible con inhibidores especificos TGF-bRI (Oida and Weiner, 2011).

\section{EI TGF- $\beta$ como mecanismo de evasión de la respuesta inmune}

Múltiples patógenos parecen explotar la vía del TGF- $\beta$ para mejorar su sobrevida: el parasito Criptosporidium parvum induce la secreción de TGF- $\beta 1$ en celulas infectadas (Maillot, et al., 2000). También, los antígenos solubles de Schistosoma mansoni tienen la capacidad de estimular la producción de TGF- $\beta$ en LT CD4 purificados e inducirles un fenotipo regulador (Zaccone, et al., 2009). Se ha implicado al TGF- $\beta$ como un inmunomodulador importante para varios virus: por ejemplo, el virus sincitial respiratorio (RSV) induce la secreción de TGF- $\beta$ en células epiteliales promoviendo su capacidad de replicación (Gibbs, et al., 2009). El virus de la influenza parece no sólo inducir la producción de TGF- $\beta$ sino de activar al mismo (Li, et al., 2015). En el caso del virus de la Hepatitis B, se ha propuesto que la producción de TGF- $\beta$ puede ser un mecanismo de evasión de la respuesta inmune y estar implicado en el desarrollo de infecciones crónicas (Karimi-Googheri, et al., 2014). Recientemente se han hecho observaciones para los norovirus y el virus del ébola que implican al TGF- $\beta$ como un inmunomodulador relevante (Kindrachuk, et al., 2014; Kocher, et al., 2014).

Es importante anotar que los modelos mencionados anteriormente son in vitro o correlaciones clínicas en humanos. La evidencia directa del papel del TGF- $\beta$ in vivo en una infección requiere el uso de modelos animales en los cuales se añada o elimine el TGF- $\beta$ durante la infección (Tabla 1). Experimentos en los cuales se añade TGF- $\beta$ fueron realizados hace numerosos años y, en efecto, se evidenció que el TGF- $\beta$ podía inhibir la respuesta inmune antiviral (Su, et al., 1993). Sin embargo, estos experimentos son difíciles de interpretar por aspectos como la vía y dosis de administración de la citocina. Por esta razón, la mayoría de experimentos recientes se han concentrado en usar ratones en los cuales se inhibe al TGF- $\beta$ ya sea en forma directa o genéticamente. Con respecto a este último tipo de experimento, se ha visto que ratones CD4dnTGF-bRII presentan un respuesta de LT CD8 antiviral aumentada y son menos susceptibles al virus de la coriomeningitis linfocítica murina (LCMV), lo que implica mecanísticamente al TGF- $\beta$ en la respuesta antiviral (Tinoco, et al., 2009). Con la misma cepa de ratones otro estudio mostró que una situación similar ocurre con el virus del Herpes (Allen, et al., 2011). No obstante, dos estudios posteriores evidenciaron que la resistencia antiviral de estos ratones estaba relacionada con la presencia de LT activados presentes en estos ratones en forma artificial dependiente del transgene (Boettler, et al., 2012; Garidou, et al., 2012). Además, estos últimos autores sugirieron que el TGF- $\beta$ jugaba un rol menor en estos modelos virales, pues en ratones normales, en los cuales se inhibió la citocina con la administración de anticuerpos específicos del TGF- $\beta$, una forma recombinante del TGF-bRII-Fc o un inhibidor de TGF-bRI, no se mejoró su capacidad de eliminar una infección crónica, aunque si aumentó la respuesta inmune antiviral (Boettler, et al., 2012; Garidou, et al., 2012). Es importante anotar que en estos experimentos no se utilizaron anticuerpos contra el LAP murino y que por lo tanto la actividad de la nueva forma de TGF- $\beta$ expresada por LT CD4 FoxP3- (descrita en el aparte anterior) pudo no haber sido inhibida (da Cunha, et al., 2015; Oida and Weiner, 2011; Rezende, et al., 2013).

Para tratar de entender el papel del TGF- $\beta$ en las células dendríticas (CD) y asesinas naturales (NK), algunos investigadores han recurrido a los ratones CD11c-dnTGF$\beta R I I$ que expresan una forma constitutiva de la versión

Tabla 1. Cepas de ratones genéticamente modificados utilizados para estudiar el papel del TGF- $\beta$ en la inmunidad contra virus

\begin{tabular}{|c|c|c|c|}
\hline Cepa de ratón & Alteración Funcional & Hallazgos principales & Referencias \\
\hline CD4dnTGF-bRII & $\begin{array}{l}\text { Expresión constitutiva temprana de } \\
\text { versión dominante negativa del TGF- } \\
\text { bRII en LT }\end{array}$ & $\begin{array}{l}\text { Se atenúa la infección por LCMV y el período de } \\
\text { latencia virus del virus Herpes. }\end{array}$ & $\begin{array}{l}\text { (Allen et al., 2011; } \\
\text { Garidou et al., 2012; } \\
\text { Tinoco et al., 2009) }\end{array}$ \\
\hline CD11c-dnTGF-bRII & $\begin{array}{l}\text { Expresión constitutiva temprana de } \\
\text { versión dominante negativa del TGF- } \\
\text { bRII en CD y NK }\end{array}$ & $\begin{array}{l}\text { Disminución del número y función de las NK pero no } \\
\text { de las CD. Se atenúa la eliminación del virus Herpes } \\
\text { y el MCMV pero no la infección crónica con LCMV. }\end{array}$ & $\begin{array}{l}\text { (Allen et al., 2011; } \\
\text { Lewis et al., 2015; } \\
\text { Marcoe et al., 2012) }\end{array}$ \\
\hline dLck-TGF-bRII & $\begin{array}{l}\text { Deleción constitutiva tardía del TGF- } \\
\text { bRII en LT }\end{array}$ & $\begin{array}{l}\text { Deficiencia en el desarrollo de LT intestinales } \\
\text { específicos de LCMV y de LThf específicos de } \\
\text { influenza en pulmón. }\end{array}$ & $\begin{array}{l}\text { (Marshall et al., 2015; } \\
\text { Sheridan et al., 2014; } \\
\text { Zhang and Bevan, 2013) }\end{array}$ \\
\hline ERcre-TGF-bRII & $\begin{array}{l}\text { Deleción inducible del TGF-bRII en } \\
\text { todas las células }\end{array}$ & $\begin{array}{l}\text { La atenuación de la señalización del TGF- } \beta \text { no afecta } \\
\text { las CD y NK y su capacidad par eliminar la infección } \\
\text { aguda de MCMV y la crónica de LCMV. }\end{array}$ & (Lewis et al., 2015) \\
\hline
\end{tabular}


dominante negativa del TGF- $\beta$ RII en dichas células. En estos ratones se evidencia una disminución del número y función de las NK pero no de las CD y se atenúa la eliminación del virus Herpes y el citomegalovirus murino (MCMV), pero no la infección crónica con LCMV (Allen, et al., 2011; Lewis, et al., 2015; Marcoe, et al., 2012). Sin embargo, de la misma manera que los ratones que expresan constitutivamente el dnTGF-bRII bajo el promotor de CD4, este efecto podría deberse a alteraciones en el desarrollo de las células.

Así mismo, se han usado ratones dLck-TGF- $\beta$ RII que tienen deleción constitutiva tardía (después de la selección positiva en el timo) del TGF- $\beta$ RII en LT (Marshall, et al., 2015; Sheridan, et al., 2014; Zhang and Bevan, 2013). Paradójicamente, en estos ratones el TGF- $\beta$ parece ser "inmunoestimulate", pues es necesario para el desarrollo de LT residentes en el intestino y Thf. Es posible que estos ratones también tengan el mismo inconveniente que los otros modelos en los cuales la deficiencia de TGF- $\beta$ es constitutiva y, por lo tanto, las poblaciones celulares se vean alteradas en su desarrollo (Ishigame, et al., 2013a; Ishigame, et al., 2013b).

Para tratar de evitar el problema de la alteración celular que ocurre en los ratones genéticamente modificados constitutivamente, recientemente se recurrió a ratones ERcreTGF- $\beta$ RII que al ser tratados con tamoxifeno tienen una deleción inducible del TGF- $\beta$ RII en todas las células del organismo. Con estos ratones se mostró que la atenuación de la señalización del TGF- $\beta$ no afecta la función de las CD ni de las NK y estas células parecen mediar la eficiente eliminación aguda de MCMV y la crónica de LCMV (Lewis , et al., 2015). En forma coherente, se ha visto que estos ratones, con deficiencia en la señalización del TGF- $\beta$ inducida en la vida adulta, no desarrollan autoinmunidad (Sledzinska, et al., 2013). Estos modelos sugieren que el TGF- $\beta$ no tiene un papel crítico en la inmunidad de los ratones. Sin embargo, esta conclusión hay que tomarla con precaución pues, entre otras alteraciones, el tratamiento con dosis de tamoxifeno similares a las que se usan para la eliminación genética del TGF- $\beta$ RII pueden tener efectos colaterales (Kim, et al., 2014). Considerando toda la evidencia disponible, podemos decir que en ninguno modelo se ha establecido claramente un rol inmunomodulador importante del TGF- $\beta$ en una infección viral in vivo.

\section{EI TGF- $\beta$ en la inmunidad contra rotavirus}

\section{Modelos in vitro}

La producción de TGF- $\beta$ por células epiteliales intestinales (CEI) estimuladas con bacterias comensales se ha descrito como un mecanismo que induce la homeostasis intestinal y en particular el ambiente tolerogénico inmune del intestino (Mileti, et al., 2009; Swiatczak and Rescigno, 2012; Zeuthen, et al., 2008). A la fecha se desconoce cómo el sistema inmune intestinal diferencia microorganismos patógenos de los no patógenos (Niess and Reinecker,
2006; Swiatczak and Rescigno, 2012). Estudios con CEI y enterocitos han mostrado que la interacción de los microorganismos con estas células es crítica, ya que los patógenos, en contraste con los no patógenos, son capaces de estimular en ellas una respuesta inflamatoria que incluye TNF- $\alpha$, IL-1 $\beta$ e IL-8 (Jung, et al., 1995; Niess and Reinecker, 2006).

Nuestros estudios sobre este tema mostraron que en CEI la infección por rotavirus induce la secreción de TGF- $\beta, \mathrm{PGE}_{2}$ e IL-8 y se incrementa el ARNm de TGF- $\beta$ (Rodríguez, et al., 2009; Rodriguez, et al., 2012). No detectamos IL-12, IL-6, IL-1 $\beta$, IL-10 o TNF- $\alpha$ en los sobrenadantes de CEI infectadas con rotavirus. La presencia del TGF- $\beta$ y de la $\mathrm{PGE}_{2}$, en conjunto con la falta de TNF- $\alpha$ e IL-1 $\beta$ (citocinas claves en la modulación de la respuesta inmune intestinal), sugirieron que los sobrenadantes de células infectadas por rotavirus son tolerogénicos y deben promover que las $\mathrm{CD}$ adyacentes a los enterocitos infectados secreten citocinas no inflamatorias (no Th1). Esto fue evidenciado directamente en un modelo en que se estimularon $\mathrm{CD}$ con virus purificado o virus proveniente de los sobrenadantes de CEI infectadas y se cocultivaron con LT CD4 vírgenes alogénicos para estudiar su diferenciación (Rodriguez, et al., 2012). Los LT con el primer estímulo se diferenciaron a LT Th1 pero con el segundo se observó una disminución de dicha respuesta. Este efecto se inhibió al pre-tratar a las CDs con anticuerpos contra el TGF- $\beta$.

Más aún, mostramos que los sobrenadantes de CIE infectadas con rotavirus liberan microvesículas capaces de inducir la muerte celular y de inhibir la proliferación de LT purificados estimulados policlonalmente (Barreto, et al., 2010). Este efecto fue en parte debido al TGF- $\beta$ presente en estas microvesículas, ya que su efecto se inhibió al tratar a las células con un inhibidor de la transduccion de la señal del TGF-bRI, la molécula SB431542. Por estar asociado a estas microvesículas, el TGF- $\beta$ puede ver potenciada su función logarítmicamente (Barreto, et al., 2010).

Estos resultados deben interpretarse en el contexto del hecho que los rotavirus parecen haber desarrollado múltiples mecanismos para evadir la respuesta inmune (Angel, et al., 2012). En particular, los rotavirus inhiben por múltipes vías (la mayoría dependiente de la proteína NSP1) al IFN de tipo I (Barro and Patton, 2005; Feng, et al., 2009). Con experimentos in vitro se ha visto que los receptores intracelulares RIG-I y/o MDA-5 reconocen la infección viral y activan los factores de transcripcion IRF3 y NF- $\kappa$ B. Estos factores de transcripción inducen expresión de IFN de tipo I y otros genes estimulados por IFN que promueven la inmunidad antiviral (Broquet, et al., 2011; Sen, et al., 2011). La proteína NSP1 de rotavirus induce la degradación de IRF3 e inhibe la actividad del NF-кB, efecto que se ha postulado como un importante mecanismo de evasión de la respuesta inmune (Arnold and Patton, 2011; Barro and Patton, 2005; Feng, et al., 2009; Graff, 
et al., 2009). Este mecanismo puede estar relacionado con el del TGF- $\beta$ mencionado anteriormente, pues se ha visto que el IRF3 inhibe la secreción de TGF- $\beta$ (Xu, et al., 2014) y los rotavirus, al inhibir el IRF3 indirectamente, podrían estimular la producción del TGF- $\beta$.

\section{EI modelo en ratones}

En nuestros estudios previos del modelo en ratones, encontramos que LT CD4 específicos de rotavirus (LTCD4-RV), aunque probablemente no tengan un efecto antiviral directo, son esenciales para el desarrollo de más del 90\% de la respuesta intestinal IgA específica del virus (Franco and Greenberg, 1997). Más aún, la respuesta de anticuerpos parece ser el mecanismo principal que media la protección contra la reinfección viral. En cuanto a los LTCD8-RV, se ha mostrado que tienen un efecto antiviral directo y pueden mediar una inmunidad parcial contra la reinfección viral (Franco and Greenberg, 1995, 1997; McNeal, et al., 1997). Un estudio de la respuesta T contra péptidos de las proteínas VP6 y VP7 de rotavirus en ratones inmunizados con virus murino (homólogo) y de simio (heterólogo) en las cepas de ratones C57BL/6 y Balb/c ilustra muy bien la respuesta inmune contra este virus (Jaimes, et al., 2005). En este estudio, se comparó la respuesta en ratones lactantes y adultos, y se analizaron los LT específicos de rotavirus presentes en diferentes órganos (Jaimes, et al., 2005). En la Tabla 2 se muestra el resumen de este trabajo con ratones adultos y del cual se puede concluir que: 1. Hay una falta de respuesta LTCD4-RV, pero relativamente buena respuesta de LTCD8-RV, después de infección con virus homólogo en ambas cepas de ratones. 2. Las respuestas de LT CD4 contra el virus heterológo, que tiene una diseminación sistémica, parecen ser más fuertes. 3. Las respuestas a ambos virus alcanzan el pico al día 5 después de infección y fueron transitorias (desaparecen después de aproximadamente una semana). 4. Las respuestas en el hígado, y en algunos casos las placas de Peyer, parecen ser más abundantes que las observadas en el bazo. La respuesta en ratones lactantes fue incluso de menor intensidad que en los adultos y confirma la pobre respuesta al virus. Un estudio que uso tetrámeros de clase I para caracterizar a los LTCD8-RV murinos (Masopust, et al., 2004) permitió concluir que éstos parecen estar presentes en cantidades más bajas que los LT específicos del virus de Sendai, que infecta la mucosa respiratoria. En conjunto, de estos dos artículos se puede concluir que la respuesta de LT, especialmente los CD4 contra rotavirus homólogos, es atenuada y transitoria. Estos hallazgos apoyan el hecho que los rotavirus están ejerciendo mecanismos de supresión de la respuesta inmune.

Como se dijo antes, uno de los mayores efectos del TGF- $\beta$ sobre el sistema inmune involucra a los LTreg (Travis and Sheppard, 2014). La infección de ratones neonatos y adultos con el virus homólogo EC indujo una población de LTreg $\mathrm{CD} 4^{+} \mathrm{CD} 25^{+} \mathrm{FoxP}^{+}$que al ser eliminada con un anticuerpo contra CD25 incrementó la respuesta $\mathrm{T}$ total y específica del virus. Sin embargo, la eliminación de los LTreg no tuvo efecto en la diarrea, la cantidad de virus excretado o la respuesta de IgA antiviral (Kim, et al., 2008). En otro estudio, más reciente, se reportaron hallazgos similares en ratones adultos en los cuales los LTreg que expresan Foxp3 fueron "suprimidos" (ratones que tienen el gen de Foxp3 con secuencias flox flanqueantes y una Cre recombinasa expresada en forma inducible con un promotor T) (Miller, et al., 2014). Ambos estudios tienen como debilidad que los marcadores CD25 y FoxP3 se expresan en LT recientemente activados, lo que puede confundir el resultado. Probablemente por esta razón, en el segundo de los estudios, algunos de los ratones cuyas células no podían expresar FoxP3 excretaron antígeno viral por 2-3 días más que los controles, hallazgo que, en este modelo, es típico de la deficiencia de LTCD8. Una posibilidad es que las células suprimidas FoxP3 ${ }^{+}$fueran LTCD8 efectores. Alternativamente, puede ser que los LTreg tengan un papel en la eliminación viral en la fase aguda de la infección, como se ha visto con los virus del Herpes o West Nile (Lanteri, et al., 2009; Lund, et al., 2008). Además, es importante tener en cuenta que en el primer estudio la eliminación de células $\mathrm{CD}_{2} 5^{+}$fue bastante pobre $(60-70 \%)$

Tabla 2. Respuesta de LT de ratones adultos de dos cepas a las proteínas VP6 y VP7 en diversos órganos, cinco días después de infección oral con rotavirus murino (homólogo) o de simio (heterólogo).

\begin{tabular}{lcccccccc}
\hline & \multicolumn{4}{c}{ Ratones C57BL/6 } & \multicolumn{3}{c}{ Ratones BALB/c } \\
\hline $\begin{array}{l}\text { Órgano estudiado/Proteína } \\
\text { viral reconocida }\end{array}$ & \multicolumn{2}{c}{ Rotavirus homólogo } & \multicolumn{2}{c}{ Rotavirus heterólogo } & \multicolumn{2}{c}{ Rotavirus homólogo } & Rotavirus heterólogo \\
\cline { 2 - 8 } & LT CD4+ & LT CD8+ & LT CD4+ & LT CD8+ & LT CD4+ & LT CD8+ & LT CD4+ & LT CD8+ \\
\hline Bazo VP6 & - & + & + & + & - & - & - \\
Bazo VP7 & - & ++ & - & +++ & - & - & - \\
P.Peyer VP6 & NR & +++ & NR & ++ & NR & NR & NR & NR \\
P. Peyer VP7 & NR & ++ & NR & ++ & NR & NR & NR & NR \\
Hígado VP6 & - & +++ & ++ & + & - & + & ++ & ++ \\
Hígado VP7 & - & +++ & - & +++ & - & $+/-$ & $+/-$ & $+/-$ \\
\hline
\end{tabular}

El número de cruces indica la frecuencia relativa de LT específicos en cada órgano. NR: no reportado. Los datos son tomados de la referencia (Jaimes et al., 2005). 
y que en el segundo no se eliminaron LTreg que expresan LAP en su superficie, pero que son negativos para FoxP3 (Oida and Weiner, 2010; Weiner, et al., 2011). Con estas salvedades, los resultados de los anteriores estudios sugieren que el efecto del TGF- $\beta$ dependiente de LTreg puede ser menor. Sin embargo, puesto que el TGF- $\beta$ tiene otros muchos efectos inmunomoduladores que no involucran a los LTreg, el impacto que su neutralización tenga en la severidad de la diarrea y cantidad de virus excretado continúa siendo una pregunta abierta.

\section{El modelo porcino}

En el modelo porcino de infección por rotavirus se ha estudiado la respuesta de citocinas intestinales y sistémicas inducidas por la infección (Azevedo, et al., 2006; Azevedo, et al., 2012; Chattha, et al., 2013). Con respecto al TGF- $\beta$ estos estudios son, en algunos casos, contradictorios y los niveles en cerdos no infectados parecen variar en forma significativa, sin una clara explicación. En el primer estudio no se pudo detectar TGF- $\beta$ ni en el plasma ni en el contenido intestinal de cerdos infectados por rotavirus (Azevedo, et al., 2006). En el segundo estudio se evidenció una disminución del TGF- $\beta$ sérico entre los días 2 y 7 pos infección. Tanto en cerdos infectados como no infectados el tratamiento con probióticos aumentó los niveles de TGF- $\beta$ en suero. A los 28 días pos infección, con o sin probióticos, el rotavirus indujo IFN- $\gamma$, IL-12, IL-4, TNF- $\alpha$, IL-6, IL-10 y TGF- $\beta$ en los contenidos intestinales, aunque sólo el TNF- $\alpha$ y la IL-10 fueron significativamente más altos. El número de células secretoras de TGF- $\beta$ en el íleon y bazo de los cerdos infectados estaba incrementado a los 28 días pos infección (Azevedo, et al., 2012).

En el tercer estudio se reprodujeron los cambios inducidos por la infección con rotavirus y probióticos en los niveles de TGF- $\beta$ en suero (Chattha, et al., 2013). En este estudio se evidenció que en el grupo de cerdos que recibieron probióticos la protección fue mayor y esto coincidió con la presencia de niveles aumentados de LTreg (caracterizados por la presencia de FoxP3) en el íleon (Chattha, et al., 2013). Como se dijo anteriormente en el aparte sobre LTreg en ratones, este hallazgo puede ser explicado por el hecho de que los LTreg juegan un papel en la eliminación viral durante la fase aguda o que las células que se están detectando con fenotipo de LTreg son en realidad LT efectores, debido a la ausencia de marcador específico e inequívoco de LTreg.

En resumen, en cerdos, durante la fase aguda de la infección, el RV parece reducir los niveles séricos de TGF- $\beta$; la producción del mismo a nivel intestinal no ha sido estudiada durante esta fase, aunque parece aumentar a las cuatro semanas post infección.

\section{Los estudios en humanos}

El estudio de la respuesta $T$ proliferativa al rotavirus en niños de 3 a 7 años de edad mostró que estas respuestas son transitorias y están presentes solamente en $35 \%$ de los niños estudiados (Makela, et al., 2004; Makela, et al., 2006). Además, al estimular células mononucleares de sangre periférica de estos niños con rotavirus se detectó aumento de mARN para IFN- $\gamma$, IL-10 y también se sugirió un aumento del TGF- $\beta$ (Makela, et al., 2006). En nuestros estudios más recientes encontramos que niños con gastroenteritis por rotavirus tienen muy bajos o niveles inferiores al ruido de fondo de LT circulantes productores de IFN- $\gamma$, IL-13, IL2, IL-10 o IL-17 (Mesa, et al., 2010). Adultos infectados por rotavirus presentan bajas frecuencias de LT CD4 que producen IL-10 e IL-2 durante la fase aguda y convaleciente, respectivamente, y bajos niveles de IFN- $\gamma$ en ambas fases (Mesa, et al., 2010). En adultos sanos la mayoría de los LTCD4-RV producen sólo IFN- $\gamma$ y una minoría IL-2, o IL-2 en combinación con IFN- $\gamma$. En células mononucleares de sangre periférica de adultos sanos, al remover las células $\mathrm{CD} 25^{+}$, bloquear el TGF- $\beta$ con su inhibidor natural el LAP, o al inhibir la via de señalización del TGF-bRI con el inhibidor SB431542, las frecuencias de LTCD4RV identificadas aumentan. A pesar de que demostramos que los niños tenían frecuencias esperadas de LTreg, no detectamos en sus células el mismo efecto que en los adultos (Mesa, et al., 2010). De acuerdo con estos resultados, muy recientemente mostramos que en adultos sanos, en comparación con LT CD4 específicos de toxoide tetánico y del virus de la influenza, LTCD4-RV parecen proliferar menos y estar enriquecidos en aquellos que sólo producen IFN- $\gamma$ (Parra, et al., 2014b). Esto está de acuerdo con un estudio complementario en que se mostró, con tetrameros de clase II, que los LT CD4 específicos de rotavirus expresan marcadores de migración intestinal y, por lo tanto, muy probablemente fueron estimulados en el intestino (Parra, et al., 2014a). En conjunto, nuestros hallazgos muestran que los LTCD4-RV parecen ser predominantemente estimulados en el intestino y cualitativamente poco eficientes, lo que podria deberse al efecto del TGF- $\beta$ como regulador negativo.

\section{Conclusiones}

El papel in vivo directo del TGF- $\beta$ en la inmunidad contra patógenos y virus en particular ha sido muy difícil de evidenciar y a la fecha no existe ningun modelo en que se haya podido demostrar un rol decisivo para esta citocina. Por esta misma razón, a pesar de la amplia evidencia que lo sugiere, no hay ninguna prueba directa de que los patógenos utilicen a esta citocina para evadir la respuesta inmune in vivo. El conjunto de resultados disponibles de nuestro laboratorio y otros laboratorios sugiere que la infección por rotavirus aumenta los niveles, de por si elevados, de TGF- $\beta$ en el medio tolerogénico intestinal y promueve una baja respuesta de LT necesaria para la inmunidad protectora antiviral. La capacidad del rotavirus de inhibir al IRF3 (vía utilizada para evadir la respuesta del IFN de tipo I) parece ligada, y puede ser complementaria, a la capacidad del virus de inducir al TGF- $\beta$. El hecho de que el rotavirus tenga una replicación predominantemente intestinal lo presenta 
como un modelo interesante para estudiar el papel de esta citocina en la inmunidad antiviral. Nuevos modelos de ratones transgenicos deficientes en TGF- $\beta$ (Aghajani, et al., 2012) y formas de inhibir a esta citocina (da Cunha, et al., 2015) pueden ser utiles para este proposito.

\section{Agradecimientos}

Agradezco a la Dra. Juana Angel por la lectura crítica de este manuscrito. Agradezco el soporte de la Pontificia Universidad Javeriana para la escritura del presente manuscrito.

\section{Conflicto de intereses}

Declaro no tener conflicto de intereses.

\section{Bibliografía}

Aghajani, K., Keerthivasan, S., Yu, Y., Gounari, F. 2012. Generation of CD4CreER(T(2)) transgenic mice to study development of peripheral CD4-T-cells. Genesis 50 (12): 908-913.

Allen, S.J., Mott, K.R., Wechsler, S.L., Flavell, R.A., Town, T., Ghiasi, H. 2011. Adaptive and innate transforming growth factor beta signaling impact herpes simplex virus 1 latency and reactivation. J Virol 85 (21): 11448-11456.

Angel, J., Franco, M.A., Greenberg, H.B. 2012. Rotavirus immune responses and correlates of protection. Curr Opin Virol 2 (4): 419-425.

Angel, J., Steele, A.D., Franco, M.A. 2014. Correlates of protection for rotavirus vaccines: Possible alternative trial endpoints, opportunities, and challenges. Hum Vaccin Immunother 10 (12): 3659-3671.

Arnold, M.M., Patton, J.T. 2011. Diversity of interferon antagonist activities mediated by NSP1 proteins of different rotavirus strains. J Virol 85 (5): 1970-1979.

Azevedo, M.S., Yuan, L., Pouly, S., Gonzales, A.M., Jeong, K.I., Nguyen, T.V., Saif, L.J. 2006. Cytokine responses in gnotobiotic pigs after infection with virulent or attenuated human rotavirus. J Virol 80 (1): 372-382.

Azevedo, M.S., Zhang, W., Wen, K., Gonzalez, A.M., Saif, L.J., Yousef, A.E., Yuan, L. 2012. Lactobacillus acidophilus and Lactobacillus reuteri modulate cytokine responses in gnotobiotic pigs infected with human rotavirus. Benef Microbes 3 (1): 33-42.

Barreto, A., Rodriguez, L.-S., Lucia Rojas, O., Wolf, M., Greenberg, H.B., Franco, M.A., Angel, J. 2010. Membrane Vesicles Released by Intestinal Epithelial Cells Infected with Rotavirus Inhibit T-Cell Function. Viral Immunology 23 (6): 595-608.

Barro, M., Patton, J.T. 2005. Rotavirus nonstructural protein 1 subverts innate immune response by inducing degradation of IFN regulatory factor 3. Proc Natl Acad Sci U S A 102 (11): 4114-4119.

Boettler, T., Cheng, Y., Ehrhardt, K., von Herrath, M. 2012. TGF-beta blockade does not improve control of an established persistent viral infection. Viral Immunol 25 (3): 232-238.
Broquet, A.H., Hirata, Y., McAllister, C.S., Kagnoff, M.F. 2011. RIG-I/MDA5/MAVS are required to signal a protective IFN response in rotavirus-infected intestinal epithelium. J Immunol 186 (3): 1618-1626.

Chattha, K.S., Vlasova, A.N., Kandasamy, S., Rajashekara, G., Saif, L.J. 2013. Divergent immunomodulating effects of probiotics on $\mathrm{T}$ cell responses to oral attenuated human rotavirus vaccine and virulent human rotavirus infection in a neonatal gnotobiotic piglet disease model. J Immunol 191 (5): 2446-2456.

da Cunha, A.P., Wu, H.Y., Rezende, R.M., Vandeventer, T., Weiner, H.L. 2015. In vivo anti-LAP mAb enhances IL$17 /$ IFN-gamma responses and abrogates anti-CD3-induced oral tolerance. Int Immunol 27 (2): 73-82.

Feng, N., Sen, A., Nguyen, H., Vo, P., Hoshino, Y., Deal, E.M., Greenberg, H.B. 2009. Variation in antagonism of the interferon response to rotavirus NSP1 results in differential infectivity in mouse embryonic fibroblasts. J Virol 83 (14): 6987-6994.

Franco, M.A., Angel, J., Greenberg, H.B. 2006. Immunity and correlates of protection for rotavirus vaccines. Vaccine $\mathbf{2 4}$ (15): 2718-2731.

Franco, M.A., Greenberg, H.B. 1995. Role of B cells and cytotoxic $\mathrm{T}$ lymphocytes in clearance of and immunity to rotavirus infection in mice. J Virol 69 (12): 7800-7806.

Franco, M.A., Greenberg, H.B. 1997. Immunity to rotavirus in T cell deficient mice. Virology 238 (2): 169-179.

Freeman, B.E., Meyer, C., Slifka, M.K. 2014. Anti-inflammatory cytokines directly inhibit innate but not adaptive CD8+ T cell functions. J Virol 88 (13): 7474-7484.

Gagliani, N., Vesely, M.C., Iseppon, A., Brockmann, L., Xu, H., Palm, N.W., de Zoete, M.R., Licona-Limon, P., Paiva, R.S., Ching, T., Weaver, C., Zi, X., Pan, X., Fan, R., Garmire, L.X., Cotton, M.J., Drier, Y., Bernstein, B., Geginat, J., Stockinger, B., Esplugues, E., Huber, S., Flavell, R.A. 2015. Th17 cells transdifferentiate into regulatory $\mathrm{T}$ cells during resolution of inflammation. Nature 523 (7559): 221-5

Garidou, L., Heydari, S., Gossa, S., McGavern, D.B. 2012. Therapeutic blockade of transforming growth factor beta fails to promote clearance of a persistent viral infection. $\mathrm{J}$ Virol 86 (13): 7060-7071.

Gibbs, J.D., Ornoff, D.M., Igo, H.A., Zeng, J.Y., Imani, F. 2009. Cell cycle arrest by transforming growth factor beta 1 enhances replication of respiratory syncytial virus in lung epithelial cells. J Virol 83 (23): 12424-12431.

Graff, J.W., Ettayebi, K., Hardy, M.E. 2009. Rotavirus NSP1 inhibits NFkappaB activation by inducing proteasomedependent degradation of beta-TrCP: a novel mechanism of IFN antagonism. PLoS Pathog 5 (1): e1000280.

Ishigame, H., Mosaheb, M.M., Sanjabi, S., Flavell, R.A. 2013 a. Truncated form of TGF-betaRII, but not its absence, induces memory CD8 $+\mathrm{T}$ cell expansion and lymphoproliferative disorder in mice. J Immunol 190 (12): 6340-6350.

Ishigame, H., Zenewicz, L.A., Sanjabi, S., Licona-Limon, P., Nakayama, M., Leonard, W.J., Flavell, R.A. 2013b. Excessive Th1 responses due to the absence of TGF-beta 
signaling cause autoimmune diabetes and dysregulated Treg cell homeostasis. Proc Natl Acad Sci U S A 110 (17): 6961-6966.

Jaimes, M.C., Feng, N., Greenberg, H.B. 2005. Characterization of homologous and heterologous rotavirus-specific T-cell responses in infant and adult mice. J Virol 79 (8): 45684579.

Jung, H.C., Eckmann, L., Yang, S.K., Panja, A., Fierer, J., Morzycka-Wroblewska, E., Kagnoff, M.F. 1995. A distinct array of proinflammatory cytokines is expressed in human colon epithelial cells in response to bacterial invasion. $\mathrm{J}$ Clin Invest 95 (1): 55-65.

Karimi-Googheri, M., Daneshvar, H., Nosratabadi, R., ZareBidaki, M., Hassanshahi, G., Ebrahim, M., Arababadi, M.K., Kennedy, D. 2014. Important roles played by TGFbeta in hepatitis B infection. J Med Virol 86 (1): 102-108.

Kim, B., Feng, N., Narvaez, C.F., He, X.S., Eo, S.K., Lim, C.W., Greenberg, H.B. 2008. The influence of CD4+ CD25+ Foxp3+ regulatory $\mathrm{T}$ cells on the immune response to rotavirus infection. Vaccine 26 (44): 5601-5611.

Kim, D., Lee, A.S., Jung, Y.J., Yang, K.H., Lee, S., Park, S.K., Kim, W., Kang, K.P. 2014. Tamoxifen ameliorates renal tubulointerstitial fibrosis by modulation of estrogen receptor alpha-mediated transforming growth factor-beta1/ Smad signaling pathway. Nephrol Dial Transplant 29 (11): 2043-2053.

Kindrachuk, J., Wahl-Jensen, V., Safronetz, D., Trost, B., Hoenen, T., Arsenault, R., Feldmann, F., Traynor, D., Postnikova, E., Kusalik, A., Napper, S., Blaney, J.E., Feldmann, H., Jahrling, P.B. 2014. Ebola virus modulates transforming growth factor beta signaling and cellular markers of mesenchyme-like transition in hepatocytes. J Virol 88 (17): 9877-9892.

Kocher, J., Bui, T., Giri-Rachman, E., Wen, K., Li, G., Yang, X., Liu, F., Tan, M., Xia, M., Zhong, W., Jiang, X., Yuan, L. 2014. Intranasal P particle vaccine provided partial crossvariant protection against human GII.4 norovirus diarrhea in gnotobiotic pigs. J Virol 88 (17): 9728-9743.

Lanteri, M.C., O'Brien, K.M., Purtha, W.E., Cameron, M.J., Lund, J.M., Owen, R.E., Heitman, J.W., Custer, B., Hirschkorn, D.F., Tobler, L.H., Kiely, N., Prince, H.E., Ndhlovu, L.C., Nixon, D.F., Kamel, H.T., Kelvin, D.J., Busch, M.P., Rudensky, A.Y., Diamond, M.S., Norris, P.J. 2009. Tregs control the development of symptomatic West Nile virus infection in humans and mice. J Clin Invest 119 (11): 3266-3277.

Lewis, G.M., Macal, M., Hesser, C., Zuniga, E.I. 2015. Constitutive But Not Inducible Attenuation Of Transforming Growth Factor-beta Signaling Increases Natural Killer Cell Responses Without Directly Affecting Dendritic Cells Early After Chronic Viral Infection. J Virol.

Li, N., Ren, A., Wang, X., Fan, X., Zhao, Y., Gao, G.F., Cleary, P., Wang, B. 2015. Influenza viral neuraminidase primes bacterial coinfection through TGF-beta-mediated expression of host cell receptors. Proc Natl Acad Sci U S A 112 (1): 238-243.
Lin, A.H., Luo, J., Mondshein, L.H., ten Dijke, P., Vivien, D., Contag, C.H., Wyss-Coray, T. 2005. Global analysis of Smad2/3-dependent TGF-beta signaling in living mice reveals prominent tissue-specific responses to injury. J Immunol 175 (1): 547-554.

Lund, J.M., Hsing, L., Pham, T.T., Rudensky, A.Y. 2008. Coordination of early protective immunity to viral infection by regulatory T cells. Science 320 (5880): 1220-1224.

Maillot, C., Gargala, G., Delaunay, A., Ducrotte, P., Brasseur, P., Ballet, J.J., Favennec, L. 2000. Cryptosporidium parvum infection stimulates the secretion of TGF-beta, IL-8 and RANTES by Caco-2 cell line. Parasitol Res $\mathbf{8 6}$ (12): 947-949.

Makela, M., Marttila, J., Simell, O., Ilonen, J. 2004. Rotavirusspecific T-cell responses in young prospectively followedup children. Clin Exp Immunol 137 (1): 173-178.

Makela, M., Oling, V., Marttila, J., Waris, M., Knip, M., Simell, O., Ilonen, J. 2006. Rotavirus-specific T cell responses and cytokine mRNA expression in children with diabetesassociated autoantibodies and type 1 diabetes. Clin Exp Immunol 145 (2): 261-270.

Marcoe, J.P., Lim, J.R., Schaubert, K.L., Fodil-Cornu, N., Matka, M., McCubbrey, A.L., Farr, A.R., Vidal, S.M., Laouar, Y. 2012. TGF-beta is responsible for NK cell immaturity during ontogeny and increased susceptibility to infection during mouse infancy. Nat Immunol 13 (9): 843-850.

Marshall, H.D., Ray, J.P., Laidlaw, B.J., Zhang, N., Gawande, D., Staron, M.M., Craft, J., Kaech, S.M. 2015. The transforming growth factor beta signaling pathway is critical for the formation of CD4 T follicular helper cells and isotype-switched antibody responses in the lung mucosa. Elife 4e04851.

Masopust, D., Vezys, V., Usherwood, E.J., Cauley, L.S., Olson, S., Marzo, A.L., Ward, R.L., Woodland, D.L., Lefrancois, L. 2004. Activated primary and memory CD $8 \mathrm{~T}$ cells migrate to nonlymphoid tissues regardless of site of activation or tissue of origin. J Immunol 172 (8): 4875-4882.

McNeal, M.M., Rae, M.N., Ward, R.L. 1997. Evidence that resolution of rotavirus infection in mice is due to both CD4 and CD8 cell-dependent activities. J Virol 71 (11): 8735-8742.

Mesa, M.C., Gutiérrez, L., Duarte-Rey, C., Angel, J., Franco, M.A. 2010. A TGF- $\beta$ mediated regulatory mechanism modulates the $\mathrm{T}$ cell immune response to rotavirus in adults but not in children. Virology 399 (1): 77-86.

Mileti, E., Matteoli, G., Iliev, I.D., Rescigno, M. 2009. Comparison of the immunomodulatory properties of three probiotic strains of Lactobacilli using complex culture systems: prediction for in vivo efficacy. PLoS One 4 (9): e7056.

Miller, A.D., Blutt, S.E., Conner, M.E. 2014. FoxP3+ regulatory $\mathrm{T}$ cells are not important for rotavirus clearance or the early antibody response to rotavirus. Microbes Infect $\mathbf{1 6}$ (1): $67-72$. 
Niess, J.H., Reinecker, H.C. 2006. Dendritic cells: the commanders-in-chief of mucosal immune defenses. Curr Opin Gastroenterol 22 (4): 354-360.

Oida, T., Weiner, H.L. 2010. TGF-beta induces surface LAP expression on murine CD4 T cells independent of Foxp3 induction. PLoS One 5 (11): e15523.

Oida, T., Weiner, H.L. 2011. Murine CD4 T cells produce a new form of TGF-beta as measured by a newly developed TGFbeta bioassay. PLoS One 6 (4): e18365.

Parra, M., Herrera, D., Calvo-Calle, J.M., Stern, L.J., ParraLópez, C.A., Butcher, E., Franco, M., Angel, J. 2014a. Circulating human rotavirus specific CD4 T cells identified with a class II tetramer express the intestinal homing receptors $\alpha 4 \beta 7$ and CCR9. Virology 452-453: 191-201.

Parra, M., Herrera, D., Jácome, M.F., Mesa, M.C., Rodríguez, L.S., Guzmán, C., Angel, J., Franco, M.A. 2014b. Circulating rotavirus-specific $\mathrm{T}$ cells have a poor functional profile. Virology 468-470C: 340-350.

Rezende, R.M., Oliveira, R.P., Medeiros, S.R., Gomes-Santos, A.C., Alves, A.C., Loli, F.G., Guimaraes, M.A., Amaral, S.S., da Cunha, A.P., Weiner, H.L., Azevedo, V., Miyoshi, A., Faria, A.M. 2013. Hsp65-producing Lactococcus lactis prevents experimental autoimmune encephalomyelitis in mice by inducing $\mathrm{CD} 4+\mathrm{LAP}+$ regulatory $\mathrm{T}$ cells. $\mathrm{J}$ Autoimmun 4045-57.

Rodríguez, L.-S., Barreto, A., Franco, M.A., Angel, J. 2009. Immunomodulators released during rotavirus infection of polarized Caco-2 cells. Viral Immunology 22 (3): 163-172.

Rodriguez, L.S., Narvaez, C.F., Rojas, O.L., Franco, M.A., Angel, J. 2012. Human myeloid dendritic cells treated with supernatants of rotavirus infected Caco- 2 cells induce a poor Th1 response. Cell Immunol 272 (2): 154-161.

Sen, A., Pruijssers, A.J., Dermody, T.S., Garcia-Sastre, A., Greenberg, H.B. 2011. The early interferon response to rotavirus is regulated by PKR and depends on MAVS/IPS1, RIG-I, MDA-5, and IRF3. J Virol 85 (8): 3717-3732.

Sledzinska, A., Hemmers, S., Mair, F., Gorka, O., Ruland, J., Fairbairn, L., Nissler, A., Muller, W., Waisman, A., Becher, B., Buch, T. 2013. TGF-beta signalling is required for $\mathrm{CD} 4(+) \mathrm{T}$ cell homeostasis but dispensable for regulatory T cell function. PLoS biology 11 (10): e1001674.
Su, H.C., Ishikawa, R., Biron, C.A. 1993. Transforming growth factor-beta expression and natural killer cell responses during virus infection of normal, nude, and SCID mice. $\mathrm{J}$ Immunol 151 (9): 4874-4890.

Swiatczak, B., Rescigno, M. 2012. How the interplay between antigen presenting cells and microbiota tunes host immune responses in the gut. Semin Immunol 24 (1): 43-49.

Tinoco, R., Alcalde, V., Yang, Y., Sauer, K., Zuniga, E.I. 2009. Cell-intrinsic transforming growth factor-beta signaling mediates virus-specific CD8 $+\mathrm{T}$ cell deletion and viral persistence in vivo. Immunity 31 (1): 145-157.

Travis, M.A., Sheppard, D. 2014. TGF-beta activation and function in immunity. Annu Rev Immunol 3251-82.

Weiner, H.L., da Cunha, A.P., Quintana, F., Wu, H. 2011. Oral tolerance. Immunol Rev 241 (1): 241-259.

Worthington, J.J., Kelly, A., Smedley, C., Bauche, D., Campbell, S., Marie, J.C., Travis, M.A. 2015. Integrin alphavbeta8Mediated TGF-beta Activation by Effector Regulatory $\mathrm{T}$ Cells Is Essential for Suppression of T-Cell-Mediated Inflammation. Immunity 42 (5): 903-915.

Xu, P., Bailey-Bucktrout, S., Xi, Y., Xu, D., Du, D., Zhang, Q., Xiang, W., Liu, J., Melton, A., Sheppard, D., Chapman, H.A., Bluestone, J.A., Derynck, R. 2014. Innate antiviral host defense attenuates TGF-beta function through IRF3mediated suppression of Smad signaling. Mol Cell 56 (6): 723-737.

Zaccone, P., Burton, O., Miller, N., Jones, F.M., Dunne, D.W., Cooke, A. 2009. Schistosoma mansoni egg antigens induce Treg that participate in diabetes prevention in NOD mice. Eur J Immunol 39 (4): 1098-1107.

Zeuthen, L.H., Fink, L.N., Frokiaer, H. 2008. Epithelial cells prime the immune response to an array of gut-derived commensals towards a tolerogenic phenotype through distinct actions of thymic stromal lymphopoietin and transforming growth factor-beta. Immunology 123 (2): 197-208.

Zhang, N., Bevan, M.J. 2012. TGF-beta signaling to T cells inhibits autoimmunity during lymphopenia-driven proliferation. Nat Immunol 13 (7): 667-673.

Zhang, N., Bevan, M.J. 2013. Transforming growth factor-beta signaling controls the formation and maintenance of gutresident memory $\mathrm{T}$ cells by regulating migration and retention. Immunity 39 (4): 687-696. 